\title{
Innovative Pedagogies-Development of an Interactive e-Portal 'School Bag'
}

\author{
Shubham Arora
}

\begin{abstract}
In this paper, we discuss the need of digital literacy and lifelong learning for developing countries like India. To cater this need, various Government and Non-Governmental Organizations are taking initiatives to introduce Educational Technology i.e. ICT in Education, Smart Classroom, interactive e-learning etc. in the educational institutions. Analyzing these requirements, a practical approach has been proposed in the present project. Using the experiences of Software Engineering, an interactive e-portal, named 'School Bag' has been developed. It is an innovative pedagogy, as interdisciplinary application of software engineering and education are evolved. School Bag is a Repository of open learning resources, having other important external links to websites. A range of audios, videos, e-books, documents, images, interactives are available in School Bag, which are share-able. For making learning a fun, Digital Game, named Kingdom of learning and fantasy has been introduced. Learners go through the study material and proceed for the question-answer session for evaluation. Immediate feedback is provided by generating scorecard automatically. Various stake holders like students, teachers, technical experts and public (from professionals to layman) can use and contribute a range of resources to this interactive e-portal.
\end{abstract}

Index Terms-Digital gaming, interactive e-portal, kingdom of learning and fantasy, school bag.

\section{INTRODUCTION}

Education is processes, events, activities and conditions those assist and encourage learning. Education may be planned or random but it helps in learning. Thus education is a service. Ref. [1] educational technology (ET) is the efficient organization of any learning system adapting or adopting methods, processes, and products to serve identified educational goals. This involves systematic identification of the goals of education, recognition of the diversity of learners' needs, the contexts in which learning will take place, and the range of provisions needed for each of these. ${ }^{1}$

The Scientific advancement has influenced every aspect of human life. From Schools to hospitals from homes to railways, from banks to entertainments, from business to technology, computer and network is the fundamental part of every sphere. So, Digital or computer literacy is essential part of daily life. Literacy is the ability to read and write. Therefore, a person who can read and write is called a Literate Person and Digital Literacy is defined as the knowledge and ability to utilize computers and related technology efficiently, with a range of

Manuscript received May 8, 2015; revised July 17, 2015.

Shubham Arora is with University Institute of Engineering and Technology (UIET), Kurukshetra University, Kurukshetra, Haryana, India (e-mail: 1ksk10@gmail.com). skills covering levels from elementary use to programming and advance problem solving.

Learning is a 'lifelong' process, from 'cradle to grave' or we can say from 'womb to tomb'. It covers a broad array of formal, informal, and non-formal learning. Fig. 1 demonstrates both the two broader concepts i.e. Digital literacy and Lifelong learning. The intersecting area of both concepts, gives rise to the various applications of innovative pedagogy. Keeping this in mind, an interactive open educational resource e-portal is developed.

\section{A. Development of an Interactive e-Portal 'School Bag'}

School Bag is an interactive websites. As we know, a school bag of student holds books, notebooks, geometry box etc. Keeping the concept of that physical school bag, a digital (virtual) school bag, an interactive web portal has been designed. Fig. 2 shows the screenshot of Homepage of School Bag. It is open to learning resources, it comprises all the resources of a school but not limited to. These resources are going to serve the human resources. For each and every person, there is something, so that learner of any age can learn. It may happen in the life of people, that for some reasons they have to stop their studies, on their way. This platform is an effort to contribute in their studies, here people from any age group can share their resources, moreover, they can interact with each other, with different ideas, skills, culture, social and moral values, and here students can become teacher for other and a teacher is also a student, learns to enhance their skills, for teaching more effectively and efficiently. School Bag is multi-dimensional. Here, people from different professions (doctors, engineers, teachers, scientist, fashion designer, Lawyers etc.) come together for counseling our young coming generation. They can contribute their resources, experiences, views, teach their subjects and also can learn more from others.

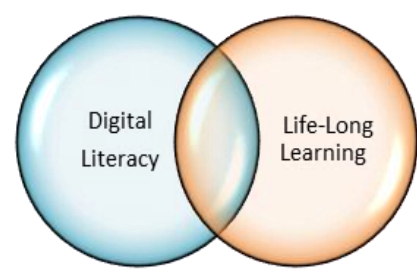

Fig. 1. Venn diagram showing the interdisciplinary approach of digital literacy and lifelong learning.

As I am also a student, it's quite difficult for kids and student to visualize the theoretical concept in the practical. Teaching Learning Material (TLM) helps to work in practical with theoretical knowledge of the concept.

School Bag, at present, is just a demo, but is not limited to this only. Its concept is very wide, broader. Innovative ideas 
are always welcomed to make it ultra-big.

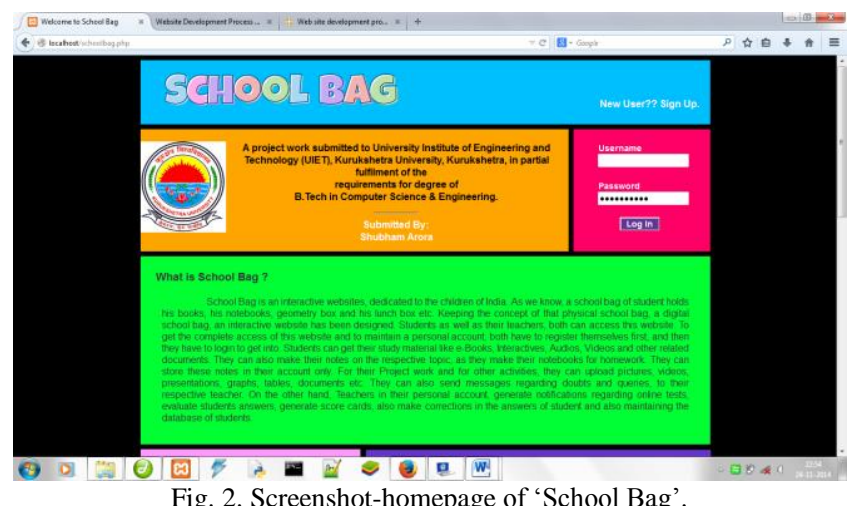

Traditional teaching methods are not sufficient to generate curiosity among students. 'Learning by Doing' and learning by digital gaming, makes the pupil to explore the concept more and more and hence they are now more curious to know their interests. School Bag allows children/learner to learn as per their convenience and at their own pace by using audio, e-books, documents (text), images, videos and interactive material.

School Bag is a ground of Social Learning, where students work together to learn and solve problems. They ask and answer questions, exchange ideas, resources and experiences. Teachers conduct online tests, interact with students on this platform, give feedback on their answers and help them to improve. Parents can also work with their kids at home see their ward's progress, helps them to improve and learn in a proper manner and get involved in their education. Communication is also enhanced between students in class.

In a class of 50 to 60 students, it's quite difficult for a teacher to track every single student's progress accurately. Every student/learner has individual learning rates and needs. So, for a teacher, there is not enough information about every student to determine their learning rate and needs. This provides teachers with detailed analytics that represents a student's engagement and performance. This also helps teachers identify each student's strengths and weaknesses which ensure that no gaps are left in a child's understanding and education. Teachers and parents can monitor the activities conducted by the students over the School Bag. So in this way a teacher can know every student better.

In the conventional education approach, all the students are not able to express themselves in class. Here, the aim is to transform students from consumers to creators, i.e. they produce their ideas as resources, so that, the peers and teachers can see what exactly a hidden talent is. The process of creation helps students achieve a deeper understanding of concepts. School Bag inspires every learner to express and create. Students can upload their creations in the form of videos, pictures and text which are showcased to other students and motivate them as well.

\section{B. Objectives of the Project}

- To develop an innovative method of self and pace learning.

- To store, preserve and provide access to a variety of digital resources to students and teachers.

- To enhance the quality of the education system of the country.
- Online evaluation using e-test system.

- To make school student computer/internet interaction friendly.

- To facilitate teachers to create and share contextual teaching and learning resources.

\section{PROJeCT Life CYCLE}

Ref. [2] a life cycle model prescribes the different activities that need to be carried out to develop a software product and the sequencing of these activities. It is also sometimes refers as the System Development Life Cycle (SDLC). A software life cycle is a series of identifiable stages/processes that a software product undergoes during a life time. A software life cycle often referred to as software process. A process was defined as a collection of work activities, action, and tasks that are preformed when some work product is to be created. Each of these activities, actions, and tasks reside within a framework or model that defines their relationship with the process and with one another. Each software engineering action is defined by a task set that identifies the work tasks that are to be completed, the work products that will be produced, the quality assurance points that will be required, and the milestones that will be used to indicate progress. Ref. [3] a generic process framework for software engineering defines five framework activities - communication, planning, modeling, construction, and deployment. Process Flow, is the aspect which describes how the framework activities and the actions and tasks that occur within each framework activity are organized with respect to sequence and time. Similar to the traditional software development process, the website development life-cycle too can be divided into different steps. Such bifurcation helps align different activities towards a progressive goal that ultimately culminates into successful project completion. Ref. [4] Fig. 3 shows the various phases of Web development life cycle.

\section{A. Analysis}

There is an essential need of digital literacy and lifelong learning for developing country like India. Analyzing these requirements, a practical approach has been proposed to develop an interactive e-portal. This gives rise to planning of the project 'School Bag'.

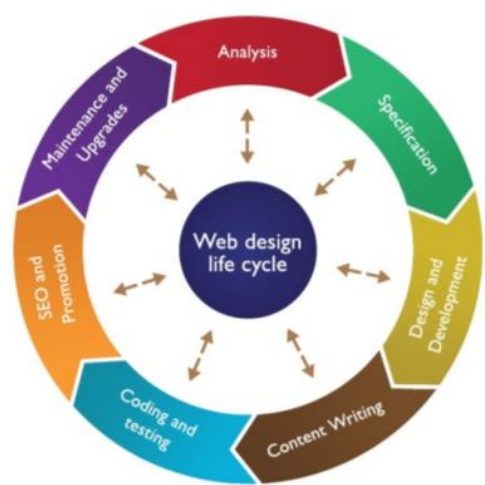

Fig. 3. Website design life cycle.

\section{B. Specifications}

1) School bag maintains a database, which holds the 
complete details of user.

2) Every user of this school bag has its own account.

3) Link of various important related sites is available. If a person is interested to see the advancement in the field of ICT in education, one need not to search it here and there, and user will directly go to link present. Related to school bag, other important sites are National repository of open educational resources-NROER (www.nroer.gov.in), National council of Educational Research and Training-NCERT, (www.ncert.nic.in), Central Institute of Educational Technology-CIET (www.ciet.nic.in), National Mission on Education through ICT- NMEICT (www.nmeict.ac.in), Sakshat (www.sakshat.ac.in).

4) School Bag is a comprehensive digital collection of resources that can be used by teachers and students in their teaching-learning process. School Bag provides a platform to teachers to create content which is localized and cater to the needs of their students. The idea is to make a variety of resources available to teachers and students so that they can use the most appropriate resource to their teaching-learning style, the needs of students and aid the learning of the subject.

5) Online-testing and immediate result/ feedback available to students.

6) A range of subject related and many other audios, videos, documents, e-books, images, interactives are available in School Bag, which are share-able.

7) Easy to understand Graphical User Interface (GUI)

8) User can add and maintain notes as notebook.

9) User can send emails to other users.

\section{Design and Development}

Tool used for designing phase is Macromedia Dreamweaver 8. Under the designing phase, there is a division for logo, statement, description, login form, signup form, and links to other related websites as well. Other web pages are designed on the same basis. Designing, if it comes to navigation, proper hyperlinks are used, which link a webpage to another web page either on the localhost or to the main server. School Bag uses the PHP script for its development part. PHP is a widely-used, open source scripting language. PHP scripts are executed on the server. It is free to download and use. PHP files can contain text, HTML, CSS, JavaScript, and PHP code. Its code is executed on the server, and the result is returned to the browser as plain HTML. PHP files have extension ".php". The main reason of using PHP is, it runs on various platforms (Windows, Linux, UNIX, Mac OS X, etc.). It is compatible with almost all servers used today (Apache, IIS, etc.) and supports a wide range of databases. Here, School Bag uses MySQL as database. XAMPP control panel v3.2.1 is the platform that supports the Apache localhost server to run PHP and MySQL. Fig. 4 shows the snapshot of XAMPP control panel.

\section{Contents of School Bag}

Contents of the school bag is 'for the student-teachers and by the student-teachers'. Means a range of resources like NCERT e-Books, Audios, Videos, Documents, Images, Interactives, and other important links are available on this platform. Each user either a learner or a teacher or any other person can contribute to this school bag means a registered person has an authority to upload and download the content. Also at the same time, the user can access the material present on this portal. Administrator has the right to check the content time to time, and can delete the unnecessary data from School Bag. A range of online tests of different subjects are also available on school bag.

\section{E. Coding and Testing}

After the analysis, specification, designing, and content phase, here comes the practical phase of website development life cycle, i.e. its implementation. Coding and testing are phase, which involve the script, codes, and functions to run the designed material on a platform. The implementation of School Bag has been done using HTML script, php coding, JavaScript, and also the MySQL database. Testing and coding works side by side. And in case of website designing and development, it is an iterative process, as after writing the code need to check its design and its working. As a new code is added to this, testing was done to check its functionality.

After a period of time the coding and testing has been done. School bag is now ready to be work on localhost/main server.

\section{F. SEO and Promotion}

Once the site is live, search engine optimization begins. Key words are analyzed, the URL is submitted to search engines, a sitemap is created, etc. SEO should be seen as an on-going process as search engines often change their strategies and requirements. Social media, such as Facebook, is another important tool that should be utilized to ensure that your site can rate as highly as possible. As presently, this is working on localhost Apache server, it is not released yet, so its SEO and promotion is not possible. After its release, this phase is required.

\section{G. Maintenance and Updating}

It is very important that websites be frequently updated to keep them fresh and interesting. It is important to keep an eye on what your competitors are doing and always try to keep one step ahead of them. Sometimes all that is required is just to update content, but there will come a time when a complete reworking of the site is required. Site activity reports such as Google's webmaster tools should be checked to see if there is any area which can be improved upon. In case of School Bag, this phase comes after its release, because when the users will use it then they'll give the feedback, accordingly it will be updates. Innovative ideas are welcomed for its advancement.

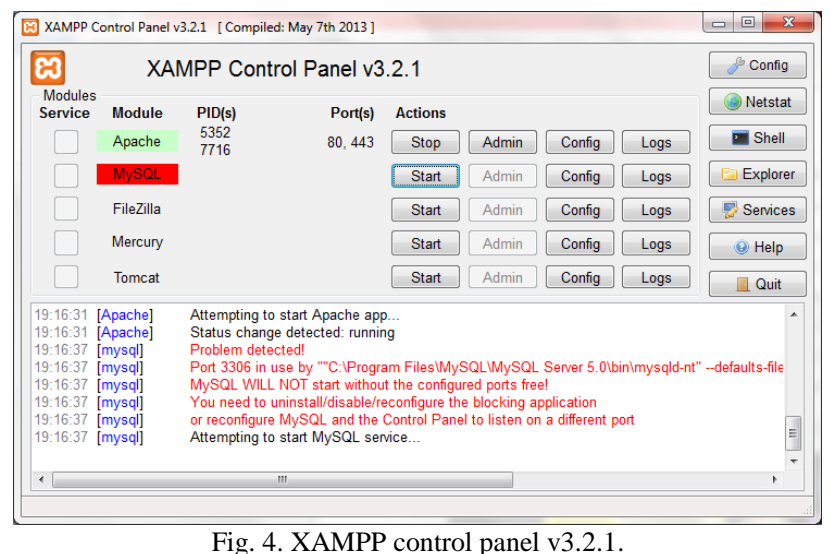

Fig. 4. XAMPP control panel v3.2.1. 


\section{WORKING OF SCHOOL BAG}

School Bag is self-understandable platform, having user-friendly graphical user interface (GUI). Before going to its homepage, one needs to start Apache localhost server and MySQL. Open its homepage. If the user is existing user, then login directly, with username and password provided. But if the user is new to School Bag, Sign Up for free. Fill the form with necessary details and submit it. Homepage is also provided with some important educational links. Now after generation of account, user is now ready to walk on the path that leads to core of School Bag. There are forms to upload images, and files. These files go to the folder on the server. Also a database is maintained, which stores the details of images and files uploaded. These databases help to retrieve these files on the webpage and can be accessed. Storage and preservation of resources is achieved. There are links to access audios, videos, and interactives. Online tests of different subjects are available. These tests are subjective and objective types, designed using form tag, and after completion of paper, user can submit the test. This answer sheet will go to the specified folder on the server, and are preserved there. Teacher, as administrator, can review these answer sheets, and give feedback to the students and their parents. This will improve the quality of education. Links to NCERT e-book is also provided. On the same navigation bar, links such as 'Add notes' and 'send an email' are present. Add notes works as a notebook, where students prepare their notes, and store them onto server, and are accessible by that student, peers and teachers. Students can append the existing files. Send an email links enables the user to send email either to peers or to teachers, or other persons. On the top, there is div, which shows any notification generated by teachers. Another div, 'Account settings' containing links such as 'update your account' makes the user to update the information provided and 'delete your account' makes the user to delete their respective account. These modifications update the database. Navigation links to some important websites is also present. There are also links to some external resources from NROER. After completing work on School Bag, user approaches 'logout'. These features make student digital literate. Fig. 5 shows the snapshot of main profile page after success login.

\section{A. Digital Game-Kingdom of Learning and Fantasy}

Kingdom of Learning and Fantasy is a self-designed, java based digital game, where learning is fun. This game comprises different subjects and deals with different classes. Here, course content of the game is the digitized version of content in books, with funny and friendly atmosphere. Learner, as per the standard, choses the subject and class and then finally go through the study material. After getting the knowledge, proceeds further for the question-answer session for evaluation. Easy, medium, and difficult are the three different levels in this scheme for completely evaluating the performance with proper and immediate feedback through automatic generated scorecard. This game make the students go through the chapter and learn continuously until they master the concept. Fig. 6 shows the screenshot of course content under Kingdom of learning and fantasy. Fig. 7 shows the gaming question-answer session of this game.

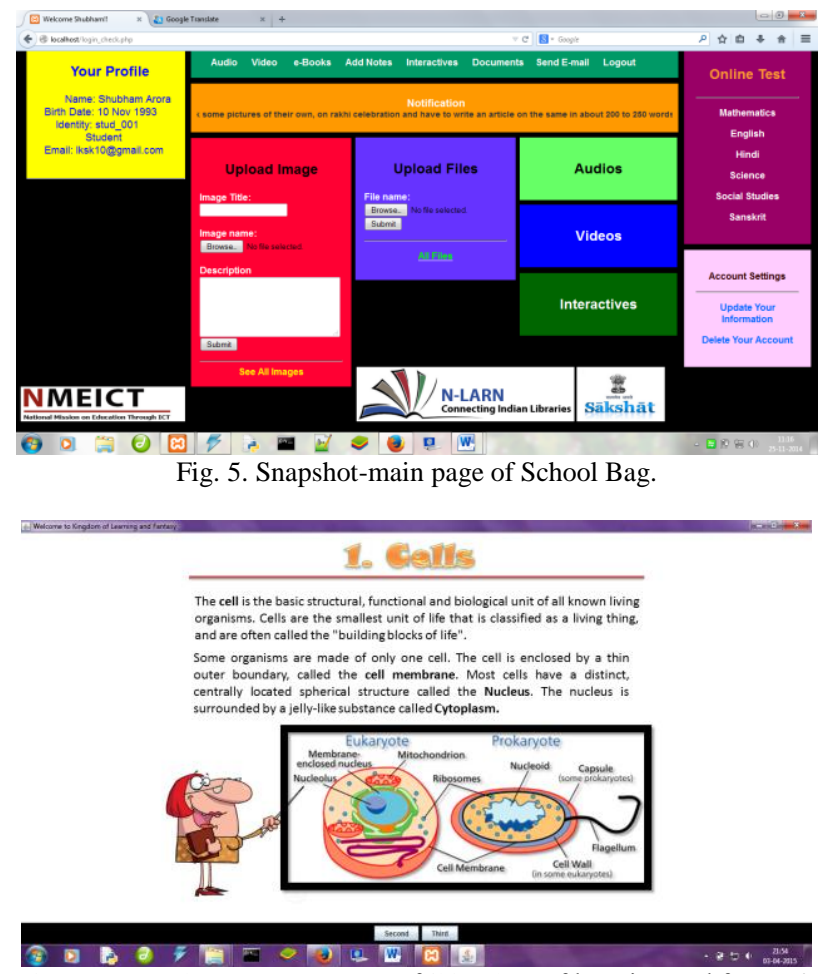

Fig. 6. Screenshot-course content of 'kingdom of learning and fantasy'.

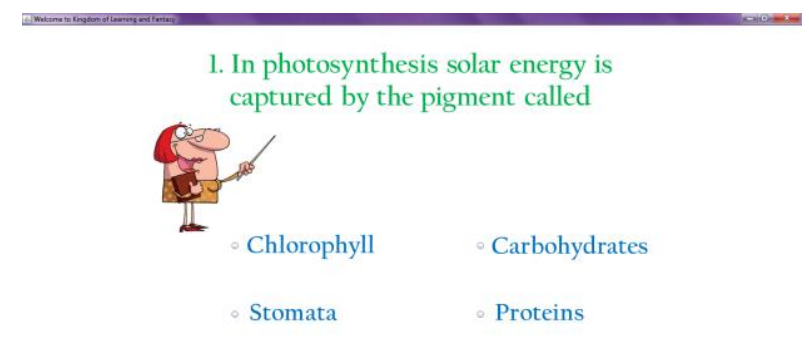

9. 7. Screenshot- question answer game session of 'kingdom of learning and fantasy'.

\section{B. Flipped Classroom}

Ref. [5]-[7] flipped classroom is a form of blended learning which brings interactive engagement pedagogy to classrooms by having students learn content online, usually at home, and homework is done in class with teachers and students discussing and solving questions. Teacher interaction with students is more personalized - guidance instead of lecturing. This is also known as backwards classroom, inverted classroom, reverse teaching, and the Thayer Method.

\section{IMPLICATIONS AND USES}

Information and Communication Technology (ICT) is an essential part of school as well as for lifelong learning. It can be used by various stakeholders i.e.

\section{A. Teachers}

Teachers can use e-content of School Bag as a teaching-learning material for their teaching. They can be well acquainted with concepts through resource libraries. Teachers can access and contribute to School Bag with their resources (audio, video, text, images, e-books), field experiences and knowledge. They can use this innovative 
e-material in their class room teaching, testing and for home assignments.

\section{B. Students}

School Bag can be helpful for students for pace level self-learning. Moreover, they can share their creativity, knowledge, ideas and experiences, social and cultural heritage. This makes classroom teaching and learning interesting and joyful. Apart from the traditional way of study i.e. class room study; students have the facility to study anywhere, even at their homes.

\section{Public}

Public covers the range of people from Professionals to layman. People from different professions (doctors, engineers, teachers, scientist, fashion designer, Lawyers etc.) come together for vocational counselling to our young generations. They can contribute their resources, information, experiences, views etc. A layman can use the resources for learning and entertainment.

\section{Technical Experts}

Computer technical experts can use their respective skills to enhance this project. They may apply their innovative and creative efforts to take this and many other projects to higher level. They may apply the new coming Technology i.e. 'virtual Reality' to the field of education for more interactivity and learning.

\section{REFERENCES}

[1] Position Paper, National Focus Group on Educational Technology 2.6, 1st ed., National Council for Educational Research and Training, (NCERT), New Delhi, India, 2006.
[2] R. Mall, Fundamentals of Software Engineering, 3rd ed., IIT Kharagpur: PHI Learning Private Limited, 2006, ch. 2, pp. 30-31.

[3] R. S. Pressman, Software Engineering: A Practitioner's Approach, 7th ed., McGraw-Hill International Edition, 2010, ch. 2, pp. 31.

[4] R. Singh. (June 21, 2013). Website design life cycle. [Online]. Available: http://www.aldezine.com/blog/website-design-life-cycle/

[5] H. Sara, "An alternate approach in the application of the thayer concept of teaching," 2010.

[6] T. Barseghian, Three Trends That Define the Future of Teaching and Learning, KQED, February 5, 2011.

[7] (2013). Clay christensen takes closer look at how online learning will disrupt K-12 education - Tech. news and analysis. [Online]. Available: Gigaom.com.

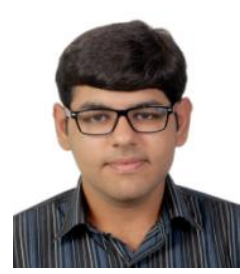

Shubham Arora is from Kurukshetra (Haryana), India and was born on November 10, 1993. Presently he is a student of bachelors of technology (computer science and engineering), final year from University Institute of Engineering and Technology (UIET) Kurukshetra University, Kurukshetra, (Haryana), India. The degree will be awarded in June, 2015.

During his summer training in 2013 at Centre for Development of Advanced Computing (CDAC), Mohali, India, he has developed a digital game, named "Kingdom of Learning and Fantasy" in core Java. From July to August, 2014, he has undergone for internship at Central Institute of Educational Technology (CIET), National Council for Educational Research and Training (NCERT), New Delhi, India. During this internship, he prepared metadata for images, mapped resources for e-content, helped in web solutions of problems and issues related to ICT. As a major project, he designed and developed an interactive e-portal for sharing and using of e-content. In his final year, he is working on Google Maps APIs.

Mr. Arora has been awarded with Central Sector Scheme of Scholarship (CSSS) in 2011 for undergraduate studies and also awarded with Chacha Nehru Scholarship for Artistic and Innovative Excellence by NCERT, New Delhi for Bal Shree Award in 2008. 